\title{
Severe Obstetric Morbidity (Near miss)
}

\author{
Vargas Hernández Víctor Manuel*, Tovar Rodríguez José María and Becerril Rodríguez Paola Rocío \\ Division of Gynecology and Obstetrics, Mexico \\ *Corresponding author: Victor Manuel Vargas Hernandez, Division of Gynecology and Obstetrics, Mexico
}

ARTICLE INFO

Received: 看 July 10, 2019

Published: 慧 July 18, 2019

Citation: Vargas Hernández Víctor $M$, Tovar Rodríguez José María, Becerril Rodríguez Paola R. Severe Obstetric Morbidity (Near miss). Biomed J Sci \& Tech Res 19(5)-2019. BJSTR. MS.ID.003353.

Keywords: Severe Obstetric Morbidity; Near Miss; Obstetric Hemorrhage; Preeclampsia Sepsis; Maternal Death

\section{ABSTRACT}

Background: A case of "Near miss maternal" or severe obstetric condition is defined as the patient at risk of dying, which survives the complication that occurred during pregnancy, delivery or at the end of the puerperium; or women who have survived the risks that endanger their lives.

Objective: to determine how many cases of severe obstetric morbidity and mortality were presented between January 2010 and December 2016, at the Hospital Juárez de México.

Material and Methods: A retrospective study was conducted, obtaining 130 cases with severe obstetric morbidity and 26 maternal deaths. The average mortality rate was $5.78 \%$ and death rate.415. The main causes of severe morbidity were obstetric hemorrhage, hypertension associated with pregnancy and sepsis.

Conclusion: An increase was observed in cases of severe maternal morbidity and decrease in maternal death; The establishment of a committee that evaluated and analyzed cases of severe obstetric morbidity improves the quality of care and treatment with a reduction in maternal death.

Abbreviations: WHO: World Health Organization; SAMM: Severe Acute Maternal Morbidity; ISSSTE : Institute of Security and Social Services of State Workers ; IMSS: Mexican Institute of Social Security; AEO: Attention to the Obstetric Emergency

\section{Background}

The World Health Organization (WHO) since 2000 established the Millennium Goals, among which is mainly to reduce maternal mortality (MM) by 75\% and universal access to reproductive health A careful examination of MM levels is a good reference for health professionals, to monitor morbidity and MM; mainly in emerging countries, since it is an indicator of economic development [1]. The concept of extreme maternal morbidity is defined by the World Health Organization (WHO) as urgent medical intervention to prevent maternal death [2]; Specialized care of all obstetric patients is recommended to perform the necessary interventions and prevent complications; However, this saturates health services and the best strategy is for support in the chain of care for women with complications [3]; however, the health status of pregnant women is not reflected only in the mortality indicators. Therefore, the concept of severe acute maternal morbidity (SAMM) is suitable for the current health delivery system. This concept is superior to the MM in calling attention to the health and reproductive life of women survivors, and is equally applicable in both developing and developed countries. In many developed countries, maternal mortality has declined to single digits, while cases of near misses are more and, therefore, useful for the evaluation of the current system [4-6]. In the INEGI (National Institute of Statistics, Geography and Informatics) analyzed the MM through preventable and avoidable deaths in excess in two periods (2002-2006 and 2007-2011), the MM are among the 48 causes of death that can be avoid; To avoid excess, the existing gaps between preventable deaths and their occurrence against non-preventable deaths are identified at some point [1]; Since 2007, Mexico has launched public policies to prioritize access to maternal health services. The Volunteer and Safe Sponsoring Committee that in 2008 promoted universal access to obstetric care, resulted in the health program "Healthy Pregnancy" [2], with priority membership to all pregnant women and family to Popular insurance (SPS).

In 2009 the Ministry of Health (SS) launched a strategy to accelerate the reduction of the MM in Mexico, along with it has the document of 05.28.2009, “General Agreement of Inter-institutional 
Collaboration for the attention to the Obstetric Emergency (AEO) between the Mexican Institute of Social Security (IMSS), the Institute of Security and Social Services of State Workers (ISSSTE) and the SS ", which establishes that all women who present obstetric complications should be treated in any of the health units of these institutions, regardless of their affiliation status, with a projection to universal medical care [1]. The factors that influence the MM are sociodemographic, cultural and access to health services, in Mexico the MM has been reduced gradually from 88.7 MM per 100 thousand live births in 1990 to 43 in 2011, has been widely reported in the

National Information Council (CONEVAL), and the Observat orio de Maternal Mortality in Mexico (WMO) which, when validated by the INEGI, publishes the results [2] years prior to verify the developments of the millennium [2]; observing in Mexico City in 2002 is 52.3 , for 2013 .

where after social programs it has decreased to 43.3 per 1,000 live births [2]; unlike at the international level, it has been observed that MM is overestimated, when evaluating mortality in women of reproductive age. According to the INEGI MM are only the tip of the iceberg whose important part is the hidden one, which is formed by patients with acute severe obstetric morbidity, whose evolution could be towards recovery, or temporary disability or death [2]; The quality indicator in obstetric care in hospitals, are cases of severe obstetric morbidity, where the largest number of patients, make the difference in the outcomes of these patients, this allows to characterize the event, identify associated causes thereof, recognize pathologies that compromise the health of pregnant women and define health actions to improve obstetric care and reduce maternal morbidity and morbidity in our country.

The causes of MM are repeated in different parts of the world, and the main ones are hemorrhage, hypertensive disorders, sepsis and complications of abortion [7-10] extreme maternal morbidity (MME) is an indicator of obstetric care, it is one of the most worldwide attention, due to its close relationship with the MM, recognizing that for each MM about 118 women suffer an MME [11]. In developed countries it has been proposed to register patients who have suffered severe acute morbidity for their actual assessment of care obstetricians. W. Stones was the first to use the Anglo-Saxon term "Near miss" to define a category of patients with morbidity so severe that it threatens their lives; he was the first to propose his study for the evaluation of the quality of obstetric care [3];

The variables used were to include essential clinical data of patients, regardless of age or parity; "Near Miss" criteria for Health Units (WHO):

a) Severe maternal Complications: Those that endanger life.

b) Serious maternal Complications: "Potentially lifethreatening conditions", this is a long list of clinical conditions, including life-threatening conditions for a patient during pregnancy, delivery and after termination of pregnancy [3].

The World Health Organization prepared the list of conditions that endanger the lives of our patients; WHO Working Group of Maternal Deaths and Morbidity Clasifications, are divided into 5 conditions: severe postpartum hemorrhage, severe preeclampsia-eclampsia, sepsis / systemic infection, and uterine rupture. Diseases which may be relevant to the outcome of women, but not a part of the chain of events that led to the outcome of them [12-17]. Critical interventions require the management of these conditions; for example, hemotransfusions, interventional radiology, exploratory laparotomy (including hysterectomy and other emergency surgeries within the abdominal cavity, excluding caesarean section) $[14,18]$. Admission to intensive care is defined as admission to a unit that provides 24 hours or more of medical supervision and that is capable of providing mechanical ventilation and intravenous vasoactive drugs to restore hemodynamic parameters.

A case of "Near miss maternal" is defined as the patient at risk of dying, but survives a complication that occurred during pregnancy, delivery or at the end of the puerperium or 42 days of termination of pregnancy; are those women who have survived life-threatening conditions (due to organic dysfunction). The indicators of processes are those that advise the mechanisms in the care of the health; The key to interventions related to the prevention and management of severe maternal complications will be used as a key to implement recommendations based on evidence $[15,19]$. Sentinel units are structures that provide facilities in the care of patients with severe complications related to pregnancy, childbirth and puerperium. (specialist maternal-fetal doctors, intensive care units, operating room, recovery area, emergency gynecology and obstetrics, blood bank, post-abortion care area, hospitalization and others) $[19,20]$.

The plan to identify patients with eligibility criteria:

Study variables

\section{A. Related with the Diagnosis}

i. Septic shock

ii. Hypovolemic shock

iii. Severe pre-eclampsia

iv. Eclampsia

B. Related to Failure or Organic Dysfunction (Near Miss Criteria) $[16,17,19,20]$

i. Cardiovascular Dysfunction: Shock, cardiac arrest (absence of pulse / Heartbeat and loss of consciousness), use of continuous vasoactive drugs. Resuscitation, severe hypoperfusion (Lactate $>5 \mathrm{mmol} / \mathrm{l}$ or $>45 \mathrm{mg} / \mathrm{dl}$ ), severe acidosis $(\mathrm{pH}<7.1)$.

ii. Renal Dysfunction: Oliguria not reactive to liquids or diuretics, dialysis due to acute renal failure, acute azotemia 
(creatinine $\geq 300 \mu \mathrm{mol} / \mathrm{ml}$, or $\geq 3.5 \mathrm{mg} / \mathrm{dl}$ )

iii. Hypopathic Dysfunction: Jaundice in the presence of preeclampsia, severe acute hyperbilirubinemia (bilirubin> $100 \mu \mathrm{mol} / \mathrm{l}$ or $>6.0 \mathrm{mg} / \mathrm{dl}$ )

iv. Respiratory Dysfunction: Acute cyanosis, wheezing, severe tachypnea (Respiratory frequency> 40 breaths per minute), severe bradypnea (respiratory rate $<6$ breaths per minute), intubation and ventilation not related to anesthesia, severe hypoxemia (O2 saturation $<90 \%$ for $\geq 60$ minutes or $\mathrm{PAO} 2$ / FiO2 <200).

v. Coagulation / Haematological Dysfunction: failure of clot formation, massive transfusion of blood or red blood cells $(\geq 5$ units), severe acute thrombocytopenia (<50 000 platelets / $\mathrm{ml})$

vi. Neurological Dysfunction: Prolonged unconsciousness (duration $\geq 12$ hours) / coma (including metabolic coma), stroke, uncontrollable seizures / epilepticus status, total paralysis

vii. Uterine Dysfunction: uterine bleeding or infection. Leads to hysterectomy

\section{Interventions Related to Management}

They are required in the management of potentially fatal diseases. The questionnaire of the World Health Organization (Near Miss) 1 was taken as a guide and evaluation instrument 1

i. Inside to the Intensive Care Unit (ICU) or Intensive Therapy: Which should be equal to or greater than 24 hours, in the unit should have active glass amines, and specialists in the field of mechanical ventilation management .

ii. Surgery (Laparotomy, including hysterectomy and surgical interventions of the abdominal cavity excluding caesarean section)

iii. Hemotransfusion with more than 5 globular packages.

The objective was to determine the prevalence of extreme maternal morbidity in the Hospital Juárez de México in the period from January 2010 to December 2016, to know the characteristics of the patients with these conditions; Calculate the ratio of extreme maternal morbidity in the Hospital Juárez de México: Severe Obstetric Morbidity. (Near miss / Total pregnant) (Near miss / Obstetric Grave.), Calculate the mortality ratio according to the most frequent causes that cause extreme maternal morbidity. We used means of central tendency (mean, median and mode) and dispersion (standard deviation) for continuous numerical variables.

The maternal severe result (RMS) rate will be determined: which refers to the number of women with life-threatening conditions plus the MM (MME + MM) per 1000 live births (NV). This indicator gives an estimate of the amount of care and resources that would be needed in an area or hospital. iv. Women with life-threatening conditions (MCAV): Refers to all women who are classified as extreme maternal morbidity (MME or near miss) and those who died. It is the sum of extreme maternal morbidity and maternal death (MCAV = MME + $\mathrm{MM}$ ). Extreme maternal morbidity rate (TMME): Refers to the number of cases of MME per 1000 live births (TMME = MME / NV).

v. Rate of mortality in women with Extreme Maternal Morbidity (MME): refers to the rate between cases of MME and maternal deaths (MME / MM). Higher rates indicate better care.

vi. Mortality index (MI): This refers to the number of maternal deaths divided by the number of women with life-threatening situations expressed as a percentage (IM = MM / MME + $\mathrm{MM})$. The highest index indicates that more women with MME die (low quality of care), while the lowest index indicates that the woman with MME who die (better quality of care).

vii. Indicators of perinatal outcomes: (for example, perinatal mortality, neonatal mortality or death rates) in the context of MME could be useful to complement the evaluation of quality of care.

The results were obtained from the review of files, ICU or Intensive Therapy and records of the Mater Code of the Hospital Juárez de México. Data was collected from 130 patients who met the inclusion criteria for patients with a diagnosis of Severe Obstetric morbidity. The most frequent complications presented by severe obstetric patients were $37 \%$ obstetric hemorrhage, secondly, hypertensive disorders of pregnancy $36 \%$ and third place sepsis and uterine rupture with $12 \%$. Oxytocin was used in $38 \%$ of cases and another uterotonic as Ergonovine and carbetocin in $62 \%$. The administration of 5 globular packages and 24-hour admission to the ICU in 59\% of cases. Contraction dystocia (which led to obstetric hysterectomy) predominated in $35 \%$ of patients. The delivery was with cesarean section $56 \%$, delivery $10 \%$, the rest correspond to ectopic pregnancies or abortions. $87 \%$ of newborns were born alive and $13 \%$ died. $51 \%$ of women resolved the urgency at 3 hours of admission to the hospital, the majority of treated women are sent from other hospital centers.

In $51 \%$ of cases, magnesium sulfate was used to prevent eclampsia. Antibiotics were used in $100 \%$, and $20 \%$ steroids for lung maturation, when the maternal condition allowed it. As a non-obstetric complication, $64 \%$ of patients had anemia (Table $1)$. The results of maternal deaths, severe obstetric morbidity and live newborns from 2013 to 2016 are recorded, data for the first 3 years are missing. An increase was observed in women with a serious obstetric condition and therefore in the ratio of a serious obstetric woman per year, due to the increase in women with a serious obstetric condition despite the decrease in maternal deaths (Table 2). There is an increase in the different rates and indices due to the increase in the number of serious obstetric patients received in the hospital. 
Table 1: Reason for Extreme Maternal Morbidity by year of study.

\begin{tabular}{|c|c|c|c|c|}
\hline Year & $\begin{array}{c}\text { Number of maternal deaths } \\
\text { per year }\end{array}$ & $\begin{array}{c}\text { Women with severe obstetric } \\
\text { condition }\end{array}$ & Live newborns n $=$ & $\begin{array}{c}\text { Reason for serious obstetric woman } \\
\text { per year (\%) }\end{array}$ \\
\hline 2013 & 5 & 19 & 1963 & 0.96 \\
\hline 2014 & 9 & 21 & 1820 & 1.15 \\
\hline 2015 & 9 & 30 & 1834 & 1.63 \\
\hline 2016 & 3 & 41 & 2064 & 1.98 \\
\hline Total & 26 & 111 & 7681 & 1.44 \\
\hline
\end{tabular}

Table 2: Rates of results of women with life-threatening conditions, extreme maternal morbidity, mortality, death rate and severe maternal result, from 2013 to 2016.

\begin{tabular}{|c|c|c|c|c|c|}
\hline Year & $\begin{array}{c}\text { Women with conditions } \\
\text { that threaten life } \\
\text { (MCAV) } \mathbf{n =}\end{array}$ & $\begin{array}{c}\text { Extreme maternal morbidity } \\
\text { rate (TMME) } \mathbf{1 0 0 0} \text { live } \\
\text { births. }\end{array}$ & $\begin{array}{c}\text { Extreme maternal morbidity } \\
\text { rate (TMME) } \mathbf{~ 1 0 0 0 ~ l i v e ~} \\
\text { births. }\end{array}$ & $\begin{array}{c}\text { Mortality } \\
\text { index (IM) }\end{array}$ & $\begin{array}{c}\text { Severe maternal } \\
\text { result (RMS) }\end{array}$ \\
\hline 2013 & 24 & 9.54 & 3.8 & .20 & 1.2 \\
\hline 2014 & 30 & 11.53 & 2.33 & .30 & 1.6 \\
\hline 2015 & 39 & 16.35 & 3.33 & .23 & .93 \\
\hline 2016 & 44 & 19.86 & 13.66 & .415 & 2.1 \\
\hline $\begin{array}{c}\text { Total 2013- } \\
2016\end{array}$ & 137 & 14.32 & 5.78 & 1.6 \\
\hline
\end{tabular}

\section{Discussion}

Although obstetric complications sometimes appear as a relatively easy alternative to maternal deaths, the difficulties remain in their definition and identification, and there is limited experience with the use of severe obstetric complications as a starting point for audits or case reviews. as a monitoring indicator the success of safe motherhood programs in low income countries [21]. Unlike maternal mortality in developed countries it has been reduced in recent years and, therefore, the analysis of acute maternal morbidity It has been added to confidential investigations into the causes of maternal deaths. The main disadvantage at this time is the lack of universal definitions of severe acute maternal morbidity. The prevalence of severe acute maternal morbidity in high-income countries ranges from 3.8 to 12 per 1,000 births. Casefatality rates may reflect the quality of maternal health care [22].

Obstetric hemorrhage in the first place, hypertensive states associated with severe pregnancy, such as eclampsia and hellp syndrome in second place and thirdly sepsis, are events that occur in most countries, [23] as the main cause of obstetric mortality and morbidity serious, in the Hospital Juárez de México, for 4 years a procedure known as "Mater Code", of obstetric urgency, was implemented; to standardize the care of women with an obstetric emergency, through a multidisciplinary group to minimize delays in the integration of diagnoses and the establishment of treatment, coordinated most of the time by the obstetrician assisted by specialized personnel in intensive and surgical therapy, the occurrence of all in this group when receiving the serious obstetric patient is important, the first minutes in the hospital unit are critical for survival, in this work in less than 3 hours the serious obstetric problem was solved and most of cases the patient was placed in intensive therapy; saving the life of the serious obstetric woman is the priority, we are still far from reaching the goal of the millennium in all of Mexico; medical and nursing personnel are being trained in procedures to save life; We present these results of the characteristics of how critical obstetric events develop and resolve.

The common complications we have are severe postpartum hemorrhage $37 \%$, and severe preeclampsia $36 \%$ and thirdly sepsis; this work is only the tip of the Iceberg of an institution that works every day, and our results can be used for later work and continue to improve obstetric and newborn care; with the following recommendations for common causes of severe obstetric morbidity:

\section{Maternal Hemorrhage}

Adopt a standard plan to assess the risk of bleeding, adoption of treatment protocols and training of health personnel that include practice drills to be prepared to respond quickly to a severe hemorrhage event.

\section{Hypertensive Disorders of Pregnancy}

Physicians and obstetric facilities need a standardized plan for the early recognition and aggressive management of hypertension during pregnancy and postpartum. The MMs described in this report were largely due to a stroke resulting from severe uncontrolled blood pressure.

\section{Clinical Warning Signs}

small changes in vital signs, changes in blood pressure, alterations in heart rate, decrease in oxygen saturation and fluctuations in temperature, are clinical warnings; most pregnant women are healthy and doctors ignore these changes; signs of clinical worsening that are not perceived as an early warning sign, resulting 
in a diagnostic and therapeutic delay. Improve communication and implementation of standardized protocols on the preventable causes of maternal morbidity and mortality, hospitals and physicians need to prioritize effective communications among nurses, obstetricians and other specialists to provide timely, responsive treatment, and / or if necessary transfer of care to another hospital if the case is presented in units with less infrastructure.

\section{Conclusion}

The number of women with severe obstetric morbidity has increased over the years, due to the implementation of the "Mater Code", which has improved the quality of critical obstetric care, mainly in hospitals with access to referred obstetric care in other states of the country. Mexican Republic in serious condition such as the Hospital Juárez de México.

\section{References}

1. Freyermuth Enciso MG, Luna Contreras M (2014) Muerte materna y muertes evitables en exceso. Propuesta metodológica para evaluar la política pública en salud. Revista Internacional de Estadística y Geografía 5(3): 44-61.

2. Elaboración del (2013) OMM a partir de la Base de datos definitiva de Mortalidad Materna, Dirección General de Información en Salud, Secretaría de Salud, México.

3. Roopa PS, Shailja Verma, Lavanya Rai, Pratap Kumar, Murlidhar V Pai, et al. (2013) Near Miss Obstetric Events and Maternal Deaths in a Tertiary Care Hospital: An Audit. Journal of Pregnancy.

4. Mohammadi S, Essén B, Fallahian M, Taheripanah R, Saleh Gargari S, et al. (2016) Maternal near-miss at university hospitals with cesarean overuse: an incident case-control study. Acta Obstet Gynecol Scand 95(7): 777-786.

5. Clark SL, Belfort MA (2017) The Case for a National Maternal Mortality Review Committee. Obstet Gynecol 130(1): 198-202.

6. Lima HM, Carvalho FH, Feitosa FE, Nunes GC (2017) Factors associated with maternal mortality among patients meeting criteria of severe maternal morbidity and near miss. Int J Gynaecol Obstet 136(3): 337343.

7. Say L, Souza JP, Pattinson RC (2011) WHO working group on Maternal Mortality and Morbidity classifications. Evaluating the quality of care for Severe Maternal Complications. Best Pract Res Clin Obstet Gynaecol 1(1): $1-30$.

8. Freyermuth Enciso MG (2016) Determinantes sociales en la Mortalidad Materna en México Revista. CONAMED 21(1): 25-32.

9. Ángeles Sánchez Bringas, Guadalupe Fabiola Pérez Baleón (2014) La morbilidad asociada al embarazo y su manejo en méxico en ángeles sánchez bringas ed. desigualdades en la procreación Trayectorias reproductivas, atención obstétrica y morbimortalidad materna en México Primera (edn.). Universidad Autónoma Metropolitana UamXochimilco 2 (edn.). Itaca, México.

10. Franco Marina FR, Lozano B Villa y, P Soliz $(2006)$ Muertes evitables: magnitud, distribución y tendencias. México, Dirección General de Información en Salud. Secretaría de Salud pp. 347.

11. Say L, Souza JP, Pattinson RC (2009) WHO working group on Maternal Mortality and Morbidity classifications. Maternal near miss--towards a standard tool for monitoring quality of maternal health care. Best Pract Res Clin Obstet Gynaecol 23(3): 287-296.

12. Stones W, Lim W, Al Azzawi F, Kelly M (1991) An investigation of maternal morbidity with identification of life-threatening 'near miss' episodes. Health Trends 23(1): 13-15.

13. Jayaratnam S, Burton A, Connan KF, de Costa C (2016) Maternal 'near miss' at Royal Darwin Hospital: An analysis of severe maternal morbidity at an Australian regional tertiary maternity unit. Aust NZJ Obstet Gynaecol 56(4): 381-386.

14. Ruy L, Prado de Mello JMH, Léa Davidson GS (2004) A mortalidade materna nas capitais brasileiras: algumas características e estimativa de um fator de ajuste. Rev bras epidemiol 7(4): 449-460.

15. Rocha Filho EA, Costa ML, Cecatti JG, Parpinelli MA, Haddad SM, et al. (2015) Contribution of antepartum and intrapartum hemorrhage to the burden of maternal near miss and death in a national surveillance study. Acta Obstet Gynecol Scand 94(1): 50-58.

16. (2016) Triage Obstétrico, Código Mater y Equipo de Respuesta Inmediata Obstétrica Lineamiento Técnico 2016 Secretaría de Salud. Centro Nacional de Equidad de Género y Salud Reproductiva.

17. (2016) Protocolo De Vigilancia Epidemiológica De La Mortalidad Materna. Bogotá: OPS.

18. Sousa MH, Cecatti JG, Hardy EE, Serruya SJ (2008) Severe maternal morbidity (near miss) as a sentinel event of maternal death. An attempt to use routine data for surveillance. Reprod Health 28(5): 6.

19. Freedman LP, Graham WJ, Brazier E, Smith JM, Ensor T, et al. (2007) Practical lessons from global safe motherhood initiatives: time for a new focus on implementation. Lancet 370(9595): 1383-1391.

20. Robillard PY, Hulsey TC, Boukerrou M, Bonsante F, Dekker G, et al. (2017) Linear Association between Maternal Age and Need of Medical Interventions at Delivery in Primiparae: A Cohort of 21,235 Singleton Births. J Matern Fetal Neonatal Med 22: 1-18.

21. Ronsmans C (2009) Severe acute maternal morbidity in low-income countries. Best Pract Res Clin Obstet Gynaecol 23(3): 305-316.

22. van Roosmalen J, Zwart J (2009) Severe acute maternal morbidity in high-income countries. Best Pract Res Clin Obstet Gynaecol 23(3): 297304.

23. Vargas HVM, Acosta AG, Moreno EMA (2012) La preeclampsia un problema de salud pública mundial. Rev Chil Obstet Ginecol 77(6): 471476.

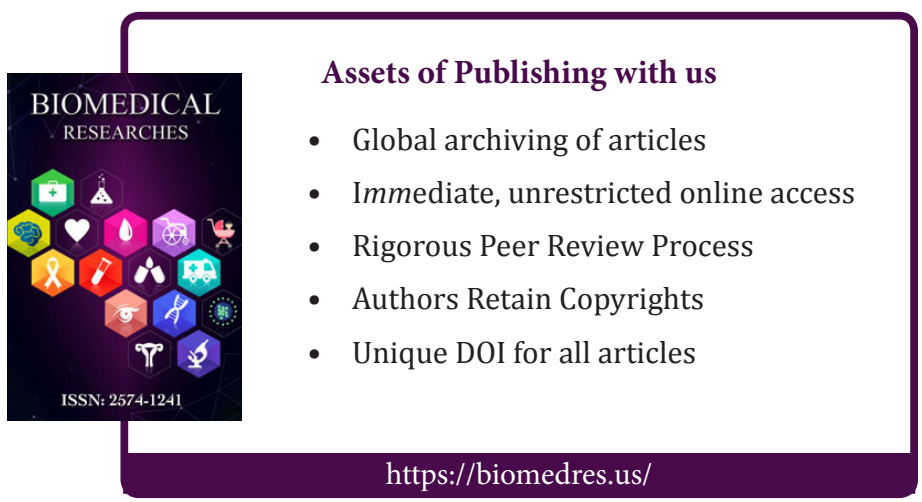

ISSN: 2574-1241

DOI: 10.26717/BJSTR.2019.19.003353

Victor Manuel Vargas Hernandez. Biomed J Sci \& Tech Res

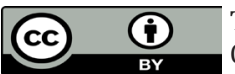

This work is licensed under Creative

Commons Attribution 4.0 License

Submission Link: https://biomedres.us/submit-manuscript.php 